\title{
Advising Doctorate Candidates And Candidates' Views During The Dissertation Process
}

Ann T. Hilliard, Bowie State University, USA

\begin{abstract}
In order to provide candidates with effective advisement, it is important for the advisor to continue to practice positive professional relationships and provide relevant academic support to candidates. The advisor should work closely with other faculty members and need to listen to the voices of candidates to ensure candidates' success. What should an advisor do overall for doctorate candidates? The advisor should provide candidates with developmental sessions, utilize the value of peer support, give relevant feedback and assessment timely and give a review of doctorate program expectations before and during the dissertation process. Too many candidates have struggled during the writing process, for example, of the dissertation proposal, because candidates enter the program with limited skills in technical writing. Therefore, a graduate writing center with competent faculty to facilitate such areas of support as basic writing skills for the behavioral and social sciences, manuscript structure, writing clearly and concisely, formatting and style, composing and displaying data results, and citing references properly so that candidates do not participate in plagiarism during the writing of the dissertation would be invaluable and relevant support to candidates. A session by the advisor should be dedicated to time management. It appears that too many doctorate candidates do not recognize that writing the dissertation requires a lot of time and time management is crucial in order for candidates to stay on top of their research and writing requirements.

This study will focus on the role of the advisor, candidates views about advisement based on candidates' experiences, a simplified view of outcome results, research designs with clarity, what is feedback, clarity with frequent feedback makes a difference, using plagiarism checking research services and evaluation of candidates' written work. The benefit of this study is to share with the broader community of doctorate program advisors and faculty committee members the need to provide the best quality experiences in advisement and instructional services to doctorate candidates to ensure their success in completing the doctorate degree program, because too many candidates complete all major course work except the actual dissertation.
\end{abstract}

Keywords: Advising; Candidate; Research Design; Feedback; Checking Tools; Evaluation

\section{INTRODUCTION}

fter informally speaking with candidates and graduates of doctorate degree programs at random, it was evident that too many candidates and graduates felt that there is a strong need to improve the whole dissertation process related to the supportive services given to doctorate candidates by advisors and committee members. Input was randomly given by over sixty-five doctorate candidates and graduates of doctorate degree programs from thirteen universities with a population of less than ten thousand students on the east coast of the United States. In order to be more effective as advisors, it is crucial for faculty members to know what doctorate candidates think about their experiences in doctorate programs. Faculty members need to be more nurturing, motivating and available to candidates during the whole dissertation process. Some candidates expressed a feeling of not being or feeling closely connected to the dissertation advisor or chairperson. Candidates further 
stated that more course work related to statistics should be given or offered a couple of semesters prior to dissertation one/two and advisement. When course work is offered several semesters prior to the dissertation course, it is difficult to remember or apply the information and to show how relevant the statistics course is to dissertation one/two. Candidates expressed that advising should be done often weekly from the beginning to the end of the dissertation experience.

Some of the best practices for advising candidates could include, but not limited to, frequent and consistent face-to-face contact so that there is a clear level of expectations from the beginning. Keeping a written account of advisement is essential to staying on track with candidates' needs. All forms of communication have shown to most useful such as face-to-face; emails, telephone calls, and all feedback should be in writing. By having information in writing, the advisor and the candidate can both communicate their thoughts clearly and all up-to-date documents can be reviewed for improvement based on suggestions made during the feedback session. Complete clarity given by the advisor, can decrease misunderstandings by the candidate and the advisor. Clear and precise feedback from the advisor can offer the candidate a higher level of productivity and accountability during the dissertation process. By providing lots of structure for doctorate candidates, the advisor can help candidates to move smoothly through this intense and highly involved period of academic research (University of Nebraska Lincoln, 2007).

\section{ROLE OF THE ADVISOR}

The overall role of the dissertation advisor is to ensure candidates' success. The advisor needs to work closely with other committee members and provide timely support to candidates through specific dissertation feedback for improvement. The advisor along with other committee members should establish and maintain a professional relationship with doctorate candidates. Being an advisor is a serious manner and responsibility. An advisor needs to see candidates as people who desire to have leadership careers and personal goals and aspiration for professional growth. The advisor should be a positive individual and should make sure that feedback is given to candidates in a constructive manner and timely. The behavior of the advisor should be positive and enthusiastic, because candidates need to feel and believe that their dissertation work is valuable and is worth researching. The advisor should be cheerful, optimistic and helpful so that the candidate can see the relevancy of the research and how the research could impact society. As an advisor, there is a need to know one's strengths and weaknesses and be willing to work with other colleagues who can support aspects of the dissertation in the area in which the advisor may not have strong expertise. Make it a practice or habit of getting back with feedback to candidates in a timely manner is a primary action for the advisor i.e. within five to ten business working days with clear and precise input for dissertation improvement. Timelessness is being emphasized here a lot, because some of the candidates and graduates stated that after emailing or leaving messages on voice mails some committee members have taken three to ten months before responding to candidates' work with such statements as, "I forgot all about you" or "I have been so busy." It would be helpful if the advisor would encourage dissertation candidates to talk with other candidates who are writing their dissertation or talk with graduates who have finished the program within the past two years for support and ideas. Make every effort as an advisor to keep candidates informed about the quality and progression of the written dissertation through appropriate feedback with clarity. Voices of candidates and graduates can tell advisors, committee members and readers a lot (Hattie \& Timperley, 2007).

In order to help candidates to be successful working on their dissertation, the role of the dissertation advisor should be clearly defined and known by the committee and doctorate candidates. Defining the standards of performance and role and expected support of dissertation advisors or supervisors should be in writing and articulated to all candidates during orientation and in an ongoing manner during doctorate candidates' development at the university (http://www.gradschool.umd.edu/phdcompletion/phdcompfaculty).

\section{CANDIDATES' VIEWS ABOUT ADVISEMENT}

Many university doctorate candidates and graduates have expressed that advisement and preparation needs improvement at many universities in the United States. Candidates expressed informally during a brief interview that universities should do a better job teaching about quantitative and qualitative research in a more meaningful and relevant manner. Faculty members and advisors need to be more reflective about the courses that they are teaching, so that candidates can gain more skill mastery in research design. Candidates specifically stated that there is a need 
for faculty members and advisors to teach candidates how to gain access to needed data-bases, collect data, and analyze data and how data should be used in the dissertation. Having one semester in a statistics course does not give enough time and application for understanding data and research designs according to many of the candidates who were interviewed.

Over sixty-five candidates enrolled and graduates of doctorate programs shared some revealing information to the researcher about their experiences as doctorate candidates or graduates. All of the candidates and graduates of doctorate degree programs individually shared their views in the outcomes of Table 1 . These individuals stated that universities offering doctorate degree programs could serve candidates more effectively if the universities were to:

1. Offer coursework in especially statistics that is relevant to an actual dissertation type.

2. Offer a dissertation technical writing course two to three semesters before the start of dissertation courses.

3. Share with candidates copies for review of successfully written dissertations.

4. Provide access and use of national and current statistical data-bases on the university campus.

5. Show students how to collect sample data and use SPSS and interpret outcomes.

6. Review and utilize common vocabulary words that are germane to research designs. Review and use several times various research designs with relevancy to the application of typical dissertation research in the social sciences.

7. Show candidates how to check their research for proper reference citation.

8. Offer more candidates developmental activities each semester that are germane to the whole research process.

9. Hire more faculty members who have demonstrated having a strong and successful background in teaching research courses and who have a proven record of being able to relate to candidates' needs and have faculty to re-teach information pertaining to typical research designs for improved skill mastery by candidates (Voices of Doctorate Candidates and Graduates, 2008-2012).

\section{Views of Doctorate Candidates Outcome Results}

\begin{tabular}{|c|c|c|c|c|c|c|c|c|c|c|c|c|}
\hline \multirow{3}{*}{\begin{tabular}{|c|} 
Table 1: \\
\# of \\
University \\
Participants
\end{tabular}} & \multicolumn{2}{|c|}{ Participants } & \multicolumn{10}{|c|}{ How to Improve the Services to Doctorate Candidates } \\
\hline & \multirow{2}{*}{$\begin{array}{c}\text { \# of } \\
\text { University } \\
\text { Candidates }\end{array}$} & \multirow{2}{*}{$\begin{array}{c}\text { \# of } \\
\text { University } \\
\text { Graduates }\end{array}$} & \multirow{2}{*}{$\begin{array}{c}\# \text { of } \\
\text { Candidates } \\
\text { Still Enrolled } \\
\text { in College }\end{array}$} & \multicolumn{9}{|c|}{$\begin{array}{c}\text { Yes or No Answers to } 1 \text { thru-9 Interview Questions } \\
\text { During Informal Interviews with doctorate candidates } \\
\text { and graduates from } 2008 \text { - Present. }\end{array}$} \\
\hline & & & & 1 & 2 & 3 & 4 & 5 & 6 & 7 & 8 & 9 \\
\hline $\mathrm{AU}$ & 4 & 2 & 2 & $\mathrm{n}$ & $\mathrm{y}$ & $\mathrm{n}$ & $\mathrm{n}$ & $\mathrm{n}$ & $\mathrm{n}$ & $\mathrm{n}$ & $\mathrm{n}$ & $\mathrm{y}$ \\
\hline BSU & 8 & 5 & 3 & $\mathrm{n}$ & $\mathrm{y}$ & $\mathrm{n}$ & $\mathrm{n}$ & $\mathrm{n}$ & $\mathrm{n}$ & $\mathrm{n}$ & $\mathrm{n}$ & $\mathrm{y}$ \\
\hline CSU & 5 & 2 & 3 & $\mathrm{n}$ & $\mathrm{y}$ & $\mathrm{n}$ & $\mathrm{n}$ & $\mathrm{n}$ & $\mathrm{n}$ & $\mathrm{n}$ & $\mathrm{n}$ & $\mathrm{y}$ \\
\hline $\mathrm{DCU}$ & 4 & 1 & 3 & $\mathrm{n}$ & $\mathrm{y}$ & $\mathrm{n}$ & $\mathrm{n}$ & $\mathrm{n}$ & $\mathrm{n}$ & $\mathrm{n}$ & $\mathrm{n}$ & $\mathrm{y}$ \\
\hline ESC & 3 & 2 & 1 & $\mathrm{n}$ & $\mathrm{y}$ & $\mathrm{n}$ & $\mathrm{n}$ & $\mathrm{n}$ & $\mathrm{n}$ & $\mathrm{n}$ & $\mathrm{n}$ & $\mathrm{y}$ \\
\hline FSU & 4 & 2 & 2 & $\mathrm{n}$ & $\mathrm{y}$ & $\mathrm{n}$ & $\mathrm{n}$ & $\mathrm{n}$ & $\mathrm{n}$ & $\mathrm{n}$ & $\mathrm{n}$ & $\mathrm{y}$ \\
\hline HU & 7 & 2 & 5 & $\mathrm{n}$ & $\mathrm{y}$ & $\mathrm{y}$ & $\mathrm{n}$ & $\mathrm{y}$ & $\mathrm{n}$ & $\mathrm{n}$ & $\mathrm{n}$ & $\mathrm{n}$ \\
\hline ISU & 5 & 1 & 4 & $\mathrm{n}$ & $\mathrm{y}$ & $\mathrm{y}$ & $\mathrm{n}$ & $\mathrm{n}$ & $\mathrm{n}$ & $\mathrm{n}$ & $\mathrm{n}$ & $\mathrm{y}$ \\
\hline LSU & 4 & 1 & 3 & $\mathrm{n}$ & $\mathrm{y}$ & $\mathrm{n}$ & $\mathrm{n}$ & $\mathrm{n}$ & $\mathrm{n}$ & $\mathrm{n}$ & $\mathrm{n}$ & $\mathrm{y}$ \\
\hline MSU & 8 & 2 & 6 & $\mathrm{n}$ & $\mathrm{y}$ & $\mathrm{n}$ & $\mathrm{n}$ & $\mathrm{n}$ & $\mathrm{n}$ & $\mathrm{n}$ & $\mathrm{y}$ & $\mathrm{n}$ \\
\hline $\mathrm{NCU}$ & 4 & 2 & 2 & $\mathrm{n}$ & $\mathrm{y}$ & $\mathrm{n}$ & $\mathrm{n}$ & $\mathrm{n}$ & $\mathrm{n}$ & $\mathrm{n}$ & $\mathrm{y}$ & $\mathrm{y}$ \\
\hline TSU & 3 & 1 & 2 & $\mathrm{n}$ & $\mathrm{y}$ & $\mathrm{y}$ & $\mathrm{n}$ & $\mathrm{n}$ & $\mathrm{n}$ & $\mathrm{n}$ & $\mathrm{y}$ & $\mathrm{y}$ \\
\hline VSU & 6 & 2 & 4 & $\mathrm{n}$ & $\mathrm{y}$ & $\mathrm{n}$ & $\mathrm{n}$ & $\mathrm{n}$ & $\mathrm{n}$ & $\mathrm{n}$ & $\mathrm{n}$ & $\mathrm{y}$ \\
\hline 13 & 65 & 25 & 40 & $13 n$ & $13 y$ & $\begin{array}{c}12 n \\
3 y\end{array}$ & $13 n$ & $\begin{array}{c}12 n \\
1 y\end{array}$ & 13n & $13 n$ & $\begin{array}{c}10 n \\
3 y\end{array}$ & $\begin{array}{c}11 y \\
2 n\end{array}$ \\
\hline
\end{tabular}

Source: Candidates and graduates participating in this research were from the thirteen participating colleges and universities. Candidates and graduates requested that their names and universities remain anonymous, but they wanted to tell their stories from 2008 to May 2012

\section{RESEARCH DESIGNS WITH CLARITY}

There are many research design tools and information. The research design in a simple definition is the structure of any scientific work. The research design gives direction and systematizes the research. An approach to 
a research problem is usually quantitative and/or qualitative or a combination of both. The major types of research designs or studies are as follows:

1. Descriptive Design aim is to observe and describe the research. This type of design is descriptive research naturalistic observation and surveys are frequently used in this design. Descriptive also asks the question, what is happening? How is something happening? Why is something happening? For Example: What is the average number of staff development hours recommended per year for teachers in the United States? What is the association between student-teacher ratio and student achievement in the state's elementary schools? How does instruction differ among teachers in the district who receive different amounts of staff development? Why do teacher qualifications influence instruction?

2. Correlation Studies aim to predict outcomes, case control study, observational study, cohort study, longitudinal study, cross section study

3. Semi-Experimental Design aim is to determine causes, field experiment, and quai-experimental design such as a dual study.

4. Experimental Design aim is to determine causes, true experimental design, double blinded experiment. Experimental will ask the question does something cause an effect.

5. Experimental or Quasi-Experimental. For Example: At the beginning of the year, the researcher randomly assigns all classes in a school district to have either a low student-teacher ratio (small class, the treatment group) or a normal student-teacher ratio (large class, the control group). At the end of the year, the researcher measures each student's achievement using the state assessment and compares the average achievement of students in the two sizes of classes. In this case the class size is the independent variable because class size is being varied or manipulated. Student achievement is the dependent variable because student achievement is being measured on specific criterion or standards. Other research aim is to explain, literature review and meta-analysis.

Each research design differs in the samples above, because each type of research design answers different types of research questions and uses different research designs to collect data. Therefore, doctorate candidates need to be totally clear about how the types of research designs differ. By re-teaching and demonstrating how various research designs should be used or work in research, a number of doctorate candidates need to participate in developmental sessions in a lab environment and this should be a practice at least four semesters prior to official research is being placed on the table to start the dissertation process. Among the interviewed doctorate candidates, several expressed that there should be separate sessions focused on qualitative and quantitative research and many illustrative examples of dissertations should be shared with candidates (http://www.ecs.org/html/issue.asp?issueid=108\&subIssueID=159).

In order for candidates to gain appropriate skills, knowledge and use of research designs, it is important for information to be taught and re-taught until there is evidence of skill mastery. Thereafter, when candidates are writing the draft dissertation, frequent feedback should be afforded to all candidates in a clear and timely manner by faculty and other committee members.

\section{WHAT IS FEEDBACK?}

There are many definitions for feedback. Responding to candidates' work in written form with the intent of improving learning is a form of feedback. Giving feedback can be orally given; however, with the nature of improving work such as a dissertation for complete clarity, it is best to give feedback always in written form. Relating directly to candidates' needs should be taken into consideration by the advisor at all times. The advisor should be honest with candidates to note that if the dissertation needs more work, more work should be done to improve the dissertation. Sharing sampler models of dissertations or making comparisons to models and exemplars based on teaching and learning could give candidates more clarity related to how to improve their own dissertation (Butler \& Winne, 2005).

Feedback should be done by the use of a rubric and other methods using NCATE standards. Feedback should relate to performance not personal matters. Feedback should be given in a descriptive manner to all candidates. This feedback from the faculty member does not imply in any manner of judgment of the candidate's 
work. This type of feedback helps the candidate to make a choice of what to change in his/her work. In essence, descriptive feedback helps the candidate to look at new ways of assessing his/her own work in another manner for improvement.

\section{CLARITY AND FREQUENT FEEDBACK MAKES THE DIFFERENCE}

In university settings, feedback from faculty to doctorate candidates should be done in a timely manner. In order for doctorate candidates to know what to do to improve their work, timeliness and specific/clear feedback should be given. It is strongly suggested that feedback for the improvement of candidates' written research for the dissertation proposal is given in written format. Information should be dated plus the citation of specific illustrations graphically should be given, if applicable, so that the candidate will have a clearer understanding as to what is expected to improve the written research for chapters 1,2 , and 3 . The frequency of feedback should also apply to completing the remaining chapters 4 and 5 for the dissertation (Kulhavy, 2007).

\section{USING PLAGIARISM CHECKING RESEARCH SERVICES}

Avoid surprises to candidates! Teach doctorate candidates through student development activities the importance of checking their research for proper reference citations and how candidates can self-check their own research. A well known checking plagiarism tool and used system is known as turnitin.com. However, there are many other citations of reference services that can be used to check for the authorization of research references such as: write check, Ithenticate and plagiartismstudent.org

Advisors should make it a point to help doctorate candidates and other students to be successful by understanding the seriousness of how to avoid plagiarizing their research. Doctorate candidates should be given a clear understanding as to how checking databases work. For example, when using turnitin.com, the advisor, student or instructor submits a paper to turnitin.com, the paper is compared to turnitin's primary databases. Turnitin.com then generates an originality report which will indicate whether the student properly cited all sources or references for the research and if additional measures or help is warranted. Advisors must always let doctorate candidates know in various discussions and in written form about the standards of academic integrity at the university including disciplinary procedures for academic misconduct during the entry orientation session or future sessions of information to all candidates enrolled in the doctorate program. A code of all students' right and responsibilities and conduct must be a part of all doctorate candidates' learning experiences. The database checking services should not be used to punish candidates, but to assist candidates in mastery and improving their work, and how to use various sources or reference guides for research and publication (http://www.paulhensel.org/teachcite.html).

\section{EVALUATION OF DOCTORATE CANDIDATES' WRITTEN WORK}

Before doctorate candidates present before the defense committee, the advisor should take the time to review all chapters of the dissertation and give candidates feedback in a clear and precise manner using a rubric. The evaluation of the written dissertation should clearly convey research within the context of the literature related to the topic. Within the introduction, there should be a strong rationale for the research topic that was chosen and the topic should be clear and focused. Chapter one should include statement of the problem, purpose of the study, questions and hypothesis, conceptual framework model, theoretical framework, significance of the study, definition of terms, limitation, scope of the study/delimitation, summary. Second, the review of the literature should be comprehensive, time-intended and relevant. The literature should have clearly described research samples, methodologies and findings with appropriate references of experts that have conducted research on such topic at a particular time. Third, the methodology should detail a description of the applicable subject, design approach, methods, procedures and statistical analyses. Specifically, the methodology chapter three should include research questions and hypothesis, purpose of the study, research design, variables, instrumentation, test validity, population, sample, data college procedures, statistical analysis of data, limitation and summary. Fourth, the results or outcomes from all research questions should be reported in a clear and concise manner. Figures, tables and other illustrations should be labeled with reference/source appropriately. Fifth, discussions of research questions, discussion and analysis of findings, implications of practices, conclusions, recommendations for future research and summary should be a major part of advisement to candidates. The conclusion should summarize recommendations that would be appropriate and clearly stated based on reflective outcomes. 
The writing quality of candidates' work throughout the document must be evaluated with clarity and precision. There must be a smooth transition from one sentence and paragraph to the next. Word choices must be appropriate, grammar, punctuation and spelling must be excellent. Candidates must know that the computer does not all always check spelling and word usage appropriately. It is recommended that doctorate candidates secure a professional and competent editor who knows how to use with accuracy, for example, the sixth edition of the American Psychological Association manual. The helpful advisor should encourage the doctorate candidate to orally present the dissertation before the advisor prior to the dissertation being presented before the defense hearing committee members formally (Moss, 2000).

\section{CONCLUSION}

The role of the advisor is to direct doctorate candidates toward success during the dissertation research experience. The advisor should demonstrate competence, caring and being supportive at all times. In order to be more effective as an advisor, the advisor should value and make it a point to listen carefully to what doctorate candidates are saying based on candidates' needs in order to be able to serve the academic research needs of all candidates in an improved manner. It is hoped that this research will help advisors and faculty committee members at universities to remain sensitive at all times to the needs voiced by doctorate candidates. It is a desire that this research will help to improve the quality of advisement and timely services rendered to doctorate candidates through improved listening skills and the re-teaching of needed skills by faculty. This research will help to show the importance of applying illustrations/demonstrations of research methods and designs. Finally, the best practice for advisement is frequent communication with candidates and descriptive timely feedback is essential. Faculty members need to encourage candidates to reference citation checking and letting candidates know the rubric that will be used to evaluate candidates' dissertation research in advance. Again, advisement intent should be to ensure candidates' success regarding the dissertation process.

\section{AUTHOR INFORMATION}

Dr. Ann T. Hilliard is an assistant professor in the College of Education, Department of Educational Studies and Leadership at Bowie State University, U.S.A. The author teaches classes related to policy, educational planning and evaluation, human resources; dissertation I/II. She has interest in data assessment research, evaluation and improving the dissertation experiences for doctorate candidates in higher education. Dr. Hilliard has earned her Ed.D. degree George Washington University; M.S. degree Johns Hopkins University; M.A.T. degree Trinity University - Washington; B.S. degree Elizabeth City State University and Consulting Certificate from Harvard University. E-mail: draph1@juno.com

\section{REFERENCES}

1. Butler, D. L., \& Winne, P. H. 2005. Feedback and self regulated learning: A theoretical synthesis. Review of Educational Research.

2. Hattie, J., \& Timperley, H. 2007. The Power of Feedback. Review of Educational Research.

3. http://www.abdsurvivalguide.com/

4. $\quad$ http://www.gradschool.umd.edu/phdcompletion/phdcompfaculty

5. $\quad$ http://www.unc.edu/depts/wcweb/handouts/dissertation.html

6. $\quad$ http://www.ecs.org/html/issue.asp?issueid=108\&subIssueID $=159$

7. $\quad$ http://www.paulhensel.org/teachcite.html

8. Kulhavy, R. W. 2007) Feedback in written instruction. Review of Educational Research.

9. Michigan State University's Graduate Student Progress Report, 2007.

10. Moss, C. M. 2000. Teaching an Intentional Learning: Examining our assumptions. Network News notes, International Network of Principals' Centers. Cambridge, MA: Harvard Graduate School of Education

11. University of Nebraska Lincoln's "Guidelines for Good Practice in Graduate Education", 2007.

12. Voices of Doctorate Candidates and Graduates of Doctorate Programs, (2008-May 2012), Small Universities on the East Coast of the United States. 